\title{
Influência da colheita mecanizada na produção cafeeira
}

\author{
Influence of the mechanized harvest in the coffee production
}

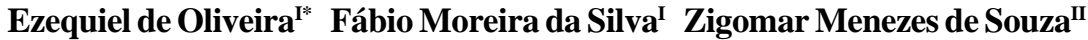 \\ Carlos Augusto Pereira de Figueiredo ${ }^{\mathrm{I}}$
}

- NOTA-

\section{RESUMO}

A colheita mecanizada de café no sul de Minas Gerais tem promovido uma melhor qualidade do produto $e$ redução de perdas, aumentando os lucros dos cafeicultores. Porém, a lavoura cafeeira ainda necessita de estudos sobre o efeito da mecanização na produtividade da cultura ao longo dos anos, uma vez que a colheita mecanizada malconduzida pode causar danos na planta. O objetivo deste trabalho foi avaliar o efeito da colheita mecanizada na produtividade da cultura cafeeira, ao longo dos anos, comparativamente com colheita no sistema manual. O delineamento utilizado foi o inteiramente casualizado, com 8 tratamentos e 3 repetições, em parcelas aleatórias contendo em média 40 plantas nas safras de 2000 a 2004, realizando a colheita tanto de forma mecanizada quanto manual. A produtividade da lavoura cafeeira não foi influenciada pela colheita mecanizada ao longo dos anos, passando a colhedora uma ou duas vezes na lavoura. O aumento de vibração das hastes promoveu uma maior quantidade de grãos colhidos, porém a desfolha aumentou proporcionalmente ao aumento de vibração. Com duas passadas da colhedora, a desfolha foi maior que a colheita manual em todas as safras agrícolas estudadas.

Palavras-chave: café arábico, mecanização agrícola, desfolha.

\section{ABSTRACT}

The mechanized harvest of coffee in the South of Minas Gerais has promoted a better product quality and loss reduction, increasing producers profit. However, studies on the effect of mechanization on productivity of the culture throught the years are needed since the mechanized harvest not will done can damage the plant. This work was aimed at evaluating the effect of mechanized harvest the coffee productivity comparing it with manual harvest. A completely randomized design with 8 treatments and 10 replications was adopted, in random parcels with 40 plants in average in the harvests of
2000 and 2004. The productivity of coffee was not influenced by mechanized harvest through the years, even when using the harvest one or twice on coffee plants field. The vibration connecting rods increase produced higher amount of harvested grains, however, the defoliation increased proportionally to the vibration whit two passes of harvester defoliation was greater than the manual harvester in all harvests evaluated periods.

Key words: arabic coffee, agricultural mechanization, defoliation.

O uso da mecanização agrícola nas diversas operações de campo é uma das grandes ferramentas que impulsionou o aumento da produção mundial de grãos, trazendo aos produtores rurais diversos benefícios, entre estes, a redução de custos e a rapidez na realização das operações de campo. Segundo KASHIMA (1990) e BARBOSA et al. (2005), o sistema de colheita mecanizada apresenta menor custo operacional e melhor qualidade dos frutos na cultura cafeeira, comparativamente ao sistema de colheita manual.

A operação de colheita do café deve ser efetuada o mais rápido possível, o que implicará melhor qualidade do produto e redução de perdas, aumentando os lucros do cafeicultor (SILVA et al. 2003). Dessa forma, a colheita mecanizada do café vem se tornando uma prática crescente com benefícios diretos na redução de custos e na qualidade de bebida; porém, pode-se observar que alguns danos são notados durante a operação de colheita, podendo acarretar prejuízos ao cafeeiro.

\footnotetext{
'Departamento de Engenharia, Universidade Federal de Lavras (UFLA), CP 3037, 37200-000, Lavras, MG, Brasil. E-mail: ezequielufla@yahoo.com.br.*Autor para correspondência.

"Universidade Estadual de Campinas (Unicamp), Faculdade de Engenharia Agrícola (FEAGRI), Campinas, SP, Brasil.
} 
Um dos principais danos causados ao cafeeiro pela ação de colhedoras, segundo BÁRTHOLO \& GUIMARÃES (1997), é a desfolha, que, na maioria das vezes, é superior a desfolha causada pela colheita manual, levando a planta a produzir menos no ano seguinte, uma vez que utilizará suas reservas para recomposição da vegetação, sendo que de tal fato resultarão estressamento da planta e redução de sua longevidade. Avaliando o número e modo de passadas de uma colhedora de café e seus efeitos na produção, SANTINATO et al. (1998) concluíram que, com duas passadas da colhedora no sentido ida e volta, a produtividade do cafeeiro não foi afetada.

Com o aperfeiçoamento das colhedoras e, sobretudo, com a adequada regulagem da vibração e da velocidade operacional, SILVA et al. (2000) observaram que a desfolha do cafeeiro causada pela colheita mecanizada com apenas uma passada da colhedora foi menor que na colheita manual, e que, com duas passadas, a desfolha equipara-se à desfolha na colheita manual. Do mesmo modo, igualmente GARCIA \& FIORAVANTE (2002), avaliando os possíveis reflexos da colheita mecanizada na cultura do café em diferentes safras, observaram que não houve prejuízos na produção da lavoura.

Em estudo sobre a influência da colheita mecanizada na produtividade do cafeeiro, SILVA et al. (2003) concluíram que, com uma ou duas passadas da colhedora, não se verificou influência na produtividade da lavoura, havendo apenas diferenças no número de brotos ortotrópicos, o qual com duas passadas da colhedora é maior, refletindo o maior tempo de aplicação da vibração sobre a planta.

Devido ao importante crescimento da colheita mecanizada na região do sul de Minas Gerais, o presente trabalho teve como objetivo avaliar o efeito da colheita mecanizada na produtividade da cultura cafeeira ao longo dos anos, comparativamente com colheita no sistema manual.

O experimento foi conduzido na fazenda Capetinga, nos anos de 2000 a 2004, localizada no município de Boa Esperança, sul de Minas Gerais, em uma área de latossolo vermelho com 3,0ha de lavoura da variedade Mundo Novo, com doze anos de idade, plantada no espaçamento de $4 \mathrm{~m}$ entre linhas e $1 \mathrm{~m}$ entre plantas, totalizando 2.500plantas ha-1.

Para a colheita, utilizou-se a colhedora tracionada modelo KTR, acoplada pelo sistema hidráulico de três pontos e acionada pela TDP a 540rpm de um trator do tipo cafeeiro, com potência nominal de $53 \mathrm{~kW}$, dotado de redutor de velocidade e tração dianteira auxiliar. Essa colhedora trabalha a cavaleiro sobre a linha das plantas, possuindo dois cilindros derriçadores com hastes vibratórias (varetas) que envolvem os cafeeiros lateralmente, derriçando os frutos pelo efeito da vibração, que caem no sistema de recolhimento, sendo, depois de ventilados, ensacados.

A fim de se avaliar a influência da colheita mecanizada na produção cafeeira, os testes foram realizados nas safras de 2000 a 2004, utilizando o delineamento inteiramente casualizado, com três repetições, contendo em média 40 plantas em cada parcela. As avaliações foram feitas com 8 diferentes tratamentos, determinando-se para cada parcela a carga pendente média, em $\left(\mathrm{L}_{\text {planta }}{ }^{-1}\right)$, o índice de frutos verde, em (\%), o volume de café colhido, $\left(\mathrm{L}_{\text {planta }}{ }^{-1}\right)$, e o volume de café caído no chão, em (\%).

Os tratamentos utilizados foram os seguintes: primeira passada com vibração variando de 650, 750 e 850 ciclos min $^{-1}$ e velocidade de $1000 \mathrm{~m} \mathrm{~h}^{-1}$ $\left(T_{1} T_{2}\right.$ e $\left.T_{3}\right)$. Na segunda passada, que foi realizada no mesmo sentido de deslocamento da primeira passada, utilizou-se a vibração de 850 ciclos min $^{-1}$ e velocidade de $800 \mathrm{~m} \mathrm{~h}^{-1}$ para todos os tratamentos $\left(\mathrm{T}_{4} \mathrm{~T}_{5}\right.$ e $\left.\mathrm{T}_{6}\right)$, a exemplo de SANTINATO et al. (1998), que também empregaram velocidade e vibração fixas na segunda passada. $\mathrm{O}$ tratamento $\left(\mathrm{T}_{7}\right)$ foi realizado com apenas uma passada da colhedora, com vibração de 850 ciclos $\mathrm{min}^{-1}$ e velocidade de $800 \mathrm{~m} \mathrm{~h}^{-1}$, e o tratamento $\left(\mathrm{T}_{8}\right)$ foi realizado com colheita manual. Todos os tratamentos descritos foram realizados nas safras de 2000, 2001 e 2002. O período entre a primeira e a segunda passada variou de 26 a 42 dias em função da maturação dos grãos do cafeeiro. Nas safras de 2003 e 2004, a colheita foi realizada manualmente sobre panos, em todas as parcelas colhidas mecanicamente nos anos anteriores.

Os resultados foram analisados estatisticamente com o auxílio do programa SISVAR e, para a análise comparativa das médias, utilizou-se o teste de Tukey, ao nível de 5\% de probabilidade.

Determinou-se a produtividade da lavoura cafeeira antes da colheita, observando-se carga pendente média de 7,0L planta-1 na safra de 2000,3,5L planta $^{-1}$ na safra de 2001 e 7,0L planta ${ }^{-1}$ na safra de 2002, com menos de $1 \%$ de grãos caídos no chão antes da primeira passada (Tabelas 1, 2 e 3).

Em todas as safras estudadas, observou-se que, com o aumento da vibração de colheita, aumentouse a quantidade de café colhido, com $5 \%$ de probabilidade, pelo teste $\mathrm{F}\left(\mathrm{T}_{1}, \mathrm{~T}_{2}\right.$ e $\left.\mathrm{T}_{3}\right)$. Resultados semelhantes foram encontrados por SILVA et al. (2002), estudando a colheita mecanizada e seletiva do café. A produtividade total média nos anos de 2000 e 2002 foram semelhantes (Tabelas 1 e 3); já no ano de 2001, a produtividade total média foi inferior à dos demais anos (Tabela 2), tratando-se de ano de baixa produtividade, 
Tabela 1 -Avaliação da produtividade da lavoura com colheita mecanizada e manual de café na safra de 2000 (carga pendente 7,0L planta ${ }^{-1}$ ).

\begin{tabular}{|c|c|c|c|c|c|c|c|}
\hline \multirow{2}{*}{ Tratamento } & Vibração & Velocidade & $\begin{array}{c}\text { Verde na } \\
\text { planta }\end{array}$ & Café colhido & $\begin{array}{c}\text { Café caído no } \\
\text { chão }\end{array}$ & $\begin{array}{c}\text { Produtividade } \\
\text { por parcela }\end{array}$ & $\begin{array}{c}\text { Produtividade } \\
\text { total }\end{array}$ \\
\hline & Ciclos $\min ^{-1}$ & $\mathrm{~m} \mathrm{~h}^{-1}$ & $\%$ & $\mathrm{~L}_{\text {planta }}{ }^{-1}$ & $\mathrm{~L}_{\text {planta }}{ }^{-1}$ & $\mathrm{~L}_{\text {planta }}{ }^{-1}$ & $\mathrm{~L}_{\text {planta }}{ }^{-1}$ \\
\hline & \multicolumn{7}{|c|}{ Primeira passada 09/06/2000 } \\
\hline $\mathrm{T}_{1}$ & 650 & 1000 & 40 & 2,60 & 0,50 & 3,10 & - \\
\hline $\mathrm{T}_{2}$ & 750 & 1000 & 40 & 3,00 & 0,55 & 3,55 & - \\
\hline \multirow[t]{2}{*}{$\mathrm{T}_{3}$} & 850 & 1000 & 40 & 3,60 & 0,68 & 4,28 & - \\
\hline & \multicolumn{7}{|c|}{ Segunda passada 15/07/2000 } \\
\hline $\mathrm{T}_{4}$ & 850 & 800 & 25 & 3,44 & 0,47 & 3,91 & 7,01 a \\
\hline $\mathrm{T}_{5}$ & 850 & 800 & 25 & 3,28 & 0,26 & 3,54 & 7,09 a \\
\hline \multirow[t]{2}{*}{$\mathrm{T}_{6}$} & 850 & 800 & 25 & 2,40 & 0,31 & 2,80 & 6,99 a \\
\hline & \multicolumn{7}{|c|}{ Única passada } \\
\hline \multirow[t]{2}{*}{$\mathrm{T}_{7}$} & 850 & 800 & 5 & 5,90 & 0,80 & 6,70 & $6,70 \mathrm{a}$ \\
\hline & \multicolumn{7}{|c|}{ Colheita manual } \\
\hline $\mathrm{T}_{8}$ & 0 & 0 & 10 & 5,35 & 1,85 & 7,20 & 7,20 a \\
\hline
\end{tabular}

Médias seguidas pela mesma letra na coluna não diferem entre si pelo teste de Tukey a 5 \% de probabilidade.

conseqüência da característica fisiológica do cafeeiro (bienalidade), ou seja, a planta alterna anos de altas e baixas produtividades.

Com relação à influência da colheita mecanizada na produtividade da lavoura, não se observou diferença significativa da produtividade total, sendo que os resultados não diferiram estatisticamente, a 5\% de probabilidade, pelo teste $F$, nas diferentes safras estudadas (Tabelas 1, 2 e 3), nas áreas colhidas tanto mecanicamente quanto manualmente.

A colheita com uma única passada da colhedora $\left(\mathrm{T}_{7}\right)$, feita com índice de verde variando de 0 a 5\%, não apresentou diferença significativa aos demais tratamentos estudados. A colheita manual apresentou produtividade média de 7,2L planta ${ }^{-1}$ na safra de 2000; 4,55L planta $^{-1}$ na de 2001 e 6,62L planta ${ }^{-1}$ na safra de 2002, não diferindo estatisticamente dos tratamentos colhidos mecanicamente. SILVA et al. (2003), avaliando a colheita totalmente mecanizada, encontraram resultados semelhantes.

Analisando-se os resultados obtidos na safra de 2003 (Tabela 4), observou-se que, nas parcelas colhidas manualmente (T8), produtividade média de 3,06 planta $^{-1}$. Para as parcelas colhidas com apenas

Tabela 2 -Avaliação da produtividade da lavoura com colheita mecanizada e manual de café na safra de 2001 (carga pendente 3,5L planta ${ }^{-1}$ ).

\begin{tabular}{|c|c|c|c|c|c|c|c|}
\hline \multirow{2}{*}{ Tratamento } & Vibração & Velocidade & $\begin{array}{l}\text { Verde na } \\
\text { planta }\end{array}$ & Café colhido & $\begin{array}{c}\text { Café caído no } \\
\text { chão }\end{array}$ & $\begin{array}{l}\text { Produtividade } \\
\text { por parcela }\end{array}$ & $\begin{array}{c}\text { Produtividade } \\
\text { total }\end{array}$ \\
\hline & Ciclos $\min ^{-1}$ & $\mathrm{M} \mathrm{h}^{-1}$ & $\%$ & L planta $^{-1}$ & L planta $^{-1}$ & L planta $^{-1}$ & L planta $^{-1}$ \\
\hline & \multicolumn{7}{|c|}{ Primeira passada 18/06/2001 } \\
\hline $\mathrm{T}_{1}$ & 650 & 1000 & 40 & 1,56 & 0,21 & 1,77 & - \\
\hline $\mathrm{T}_{2}$ & 750 & 1000 & 40 & 1,70 & 0,29 & 1,99 & - \\
\hline \multirow[t]{2}{*}{$\mathrm{T}_{3}$} & 850 & 1000 & 40 & 1,85 & 0,34 & 2,19 & - \\
\hline & \multicolumn{7}{|c|}{ Segunda passada 14/07/2001 } \\
\hline $\mathrm{T}_{4}$ & 850 & 800 & 25 & 1,40 & 0,23 & 1,63 & $3,40 \mathrm{a}$ \\
\hline $\mathrm{T}_{5}$ & 850 & 800 & 25 & 1,28 & 0,12 & 1,40 & $3,39 \mathrm{a}$ \\
\hline \multirow[t]{2}{*}{$\mathrm{T}_{6}$} & 850 & 800 & 25 & 1,35 & 0,07 & 1,42 & $3,61 \mathrm{a}$ \\
\hline & \multicolumn{7}{|c|}{ Única passada } \\
\hline \multirow[t]{2}{*}{$\mathrm{T}_{7}$} & 850 & 800 & 5 & 2,85 & 0,75 & 0 & $3,60 \mathrm{a}$ \\
\hline & \multicolumn{7}{|c|}{ Colheita manual } \\
\hline $\mathrm{T}_{8}$ & 0 & 0 & 5 & 4,55 & 0 & 0 & 4,55 a \\
\hline
\end{tabular}

Médias seguidas pela mesma letra na coluna não diferem entre si pelo teste de Tukey a 5 \% de probabilidade.

Ciência Rural, v.37, n.5, set-out, 2007. 
Tabela 3 -Avaliação da produtividade da lavoura com colheita mecanizada e manual de café na safra de 2002 (carga pendente 7,0L planta ${ }^{-1}$ ).

\begin{tabular}{|c|c|c|c|c|c|c|c|}
\hline \multirow{2}{*}{ Tratamento } & Vibração & Velocidade & $\begin{array}{c}\text { Verde na } \\
\text { planta }\end{array}$ & Café colhido & $\begin{array}{c}\text { Café caído no } \\
\text { chão }\end{array}$ & $\begin{array}{l}\text { Produtividade } \\
\text { por parcela }\end{array}$ & $\begin{array}{c}\text { Produtividade } \\
\text { total }\end{array}$ \\
\hline & Ciclos $\min ^{-1}$ & $\mathrm{~m} \mathrm{~h}^{-1}$ & $\%$ & L planta $^{-1}$ & $\mathrm{~L}_{\text {planta }}{ }^{-1}$ & $\mathrm{~L}_{\text {planta }}{ }^{-1}$ & $\mathrm{~L}_{\text {planta }}{ }^{-1}$ \\
\hline & \multicolumn{7}{|c|}{ Primeira passada 18/05/2002 } \\
\hline $\mathrm{T}_{1}$ & 650 & 1000 & 40 & 3,35 & 0,32 & 3,67 & - \\
\hline $\mathrm{T}_{2}$ & 750 & 1000 & 40 & 4,17 & 0,30 & 4,47 & - \\
\hline \multirow[t]{2}{*}{$\mathrm{T}_{3}$} & 850 & 1000 & 40 & 4,20 & 0,45 & 4,65 & - \\
\hline & \multicolumn{7}{|c|}{ Segunda passada 30/06/2002 } \\
\hline $\mathrm{T}_{4}$ & 850 & 800 & 25 & 3,20 & 0,23 & 3,43 & $7,10 \mathrm{a}$ \\
\hline $\mathrm{T}_{5}$ & 850 & 800 & 25 & 2,48 & 0,17 & 2,65 & $7,12 \mathrm{a}$ \\
\hline \multirow[t]{2}{*}{$\mathrm{T}_{6}$} & 850 & 800 & 25 & 2,18 & 0,25 & 2,43 & $7,08 \mathrm{a}$ \\
\hline & \multicolumn{7}{|c|}{ Única passada } \\
\hline \multirow[t]{2}{*}{$\mathrm{T}_{7}$} & 850 & 800 & 5 & 5,74 & 0,98 & 6,72 & $6,72 \mathrm{a}$ \\
\hline & \multicolumn{7}{|c|}{ Colheita manual } \\
\hline $\mathrm{T}_{8}$ & 0 & 0 & 5 & 5,79 & 0,83 & 6,62 & $6,62 \mathrm{a}$ \\
\hline
\end{tabular}

Médias seguidas pela mesma letra na coluna não diferem entre si pelo teste de Tukey a 5 \% de probabilidade.

uma passada da colhedora (T7), a produtividade média foi de 4,70L planta ${ }^{-1}$ e, nas parcelas colhidas com duas passadas da colhedora (T1 a T6), a produtividade média foi de 2,30L planta-1, notando-se uma tendência de queda de produtividade para os tratamentos colhidos com duas passadas da colhedora, porém com diferença não-significativa a 5\% de probabilidade, pelo teste $\mathrm{F}$. Neste ano, a baixa produtividade é justificada pela característica fisiológica do cafeeiro. Observou-se ainda, nas parcelas colhidas com duas passadas da colhedora, maior número de brotos no terço superior dos ramos plagiotrópicos, em relação aos demais tratamentos.

Para a safra de 2004, tratando-se de ano de elevada produtividade, com 13,70L planta $^{-1}$, os resultados médios de produtividade em função dos tratamentos aplicados estão apresentados na tabela 4, com diferenças não significativas, o que demonstra que a colheita mecanizada ao longo dos anos não está comprometendo a produtividade da cultura do café. A variação de produtividade entre anos alternados é uma

Tabela 4 - Avaliação da produtividade da lavoura cafeeira com colheita manual nas safras de 2003 e 2004.

\begin{tabular}{lcc}
\hline & \multicolumn{2}{c}{ Produtividade média $\left(\mathrm{L} \mathrm{planta}^{-1}\right)$} \\
\cline { 2 - 3 } Tratamentos & Safra 2003 & Safra 2004 \\
\hline T1/T4 & $1,84 \mathrm{~b}$ & $14,87 \mathrm{a}$ \\
T2/T5 & $2,18 \mathrm{a}$ & $14,48 \mathrm{a}$ \\
T3/T6 & $2,89 \mathrm{a}$ & $13,58 \mathrm{a}$ \\
T7 & $4,70 \mathrm{a}$ & $13,15 \mathrm{a}$ \\
T8 & $3,06 \mathrm{a}$ & $12,41 \mathrm{a}$ \\
\hline
\end{tabular}

característica fisiológica dos cafeeiros. Resultados semelhantes foram observados por GARCIA \& FIORAVANTE, 2002 e por SANTINATO et al., 1998.

Com relação à desfolha, observou-se que o aumento da vibração reflete-se diretamente no aumento da desfolha, concordando com os resultados obtidos por SILVA et al. (2003). Na safra de 2000, a soma da desfolha da primeira com a segunda passada variou de 675 a $806 \mathrm{~g}$ planta $^{-1}$, diferindo em $5 \%$ de significância pelo teste de Tukey da desfolha causada pela colheita manual, com 604g planta $^{-1}$. Com duas passadas, a desfolha foi, em média, $11,80 \%$ superior à desfolha na colheita manual. Quando se considerou a colheita com uma única passada da colhedora, a desfolha foi menor que na colheita manual em 15,89\%, porém com diferenças não-significativas pelo teste de Tukey a 5\% de probabilidade.

A desfolha na safra de 2001 seguiu a mesma tendência da safra de 2000, sendo que a desfolha com duas passadas continuou maior em relação a uma única passada da colhedora e também à colheita manual. Na produtividade na safra de 2002 provavelmente não houve reflexos da desfolha do ano anterior, pois observou-se que as maiores produtividades nos tratamentos com maiores desfolhas. Na safra de 2002, a desfolha foi mais elevada em, reflexo à grande infestação de ferrugem Hemileia vastatriz observada na área experimental, variando de 1.214 a 1.379 g planta $^{-1}$, nos tratamentos com duas, passados contra $629 \mathrm{~g}$ planta $^{-1}$, na colheita manual, diferindo em 5\% de probabilidade pelo teste de Tukey. Provavelmente com o aumento da desfolha nas duas passadas houve maior interferênciana na baixa produtividade dos tratamentos 
colhidos na safra de 2003. De forma semelhate, SILVA et al. (2003) também encontraram aumento da desfolha na cultura do café em áreas colhidas mecanicamente com duas passadas.

Sendo assim, com base nos resultados observou-se que a produtividade da lavoura cafeeira não foi influenciada pela colheita mecanizada ao longo dos anos, passando-se a colhedora uma ou duas vezes na lavoura. $\mathrm{O}$ aumento de vibração promoveu um maior volume de grãos colhidos, porém a desfolha aumentou proporcionalmente, sendo que, com duas passadas da colhedora, a desfolha foi maior que a desfolha na colheita manual em todas as safras agrícolas estudadas.

\section{AGRADECIMENTOS}

Ao Conselho Nacional de desenvolvimento Científico e Tecnológico, pela concessão de bolsa aos pesquisadores Silva, Oliveira e Figueiredo, e à Fundação de Amparo à Pesquisa do Estado de Minas Gerais, pela concessão de bolsa a Souza.

\section{REFERÊNCIAS}

BARBOSA, J.A. et al. Desempenho operacional de derriçadores mecânicos portáteis, em diferentes condições de lavouras cafeeiras. Revista Brasileira de Engenharia Agrícola e Ambiental, Campina Grande, v.9, n.1, p.129-132, 2005.

BÁRTHOLO, G.F.; GUIMARÃES, P.T.G. Cuidados na colheita e preparo do café. Informe Agropecuário, Belo Horizonte, v.18, n. 187, p.33-42, 1997.
GARCIA, A.W.R.; FIORAVANTE, N. Efeito do uso de derriçadoras de café portáteis na produtividade do cafeeiro no ano seguinte. In. CONGRESSO BRASILEIRO DE PESQUISAS CAFEEIRAS. 28., 2002, Caxambu, MG. Anais... Rio de Janeiro: MAPA-PROCAFÉ, 2002. p.51-52.

KASHIMA, T. A colheita mecanizada do café: produtos, desempenho e custos. In: CICLOS DE ESTUDOS SOBRE MECANIZAÇÃO AGRÍCOLA, 4., 1990, Campinas, SP. Anais... Campinas: Fundação CARGILL, 1990. p.234-246.

SANTINATO, R. et al. Número e modo de passada da colhedora K3-jacto e seu efeitos na produção do cafeeiro. In: CONGRESSO BRASILEIRO DE PESQUISAS CAFEEIRAS. 24., 1998, Poços de Caldas, MG. Anais... Rio de Janeiro: MAPA-PROCAFÉ, 1998. p.60-61.

SILVA, F.M. et al. Desempenho operacional da colheita mecanizada com varias passadas da colhedora de café. In: CONGRESSO BRASILEIRO DE PESQUISAS CAFEEIRAS. 26., 2000, Marília, SP. Anais... Rio de Janeiro: MAPA-PROCAFÉ, 2000. p.345-347.

SILVA, F.M. et. al. Avaliação da colheita mecanizada e seletiva do café. In. CONGRESSO BRASILEIRO DE PESQUISAS CAFEEIRAS. 28., 2002, Caxambu, MG. Anais... Rio de Janeiro: MAPA-PROCAFÉ, 2002. p.150-152.

SILVA, F.M. et al. Avaliação da colheita do café totalmente mecanizada. Engenharia Agrícola, Jaboticabal, v.23, n.2, p.309-315, 2003. 